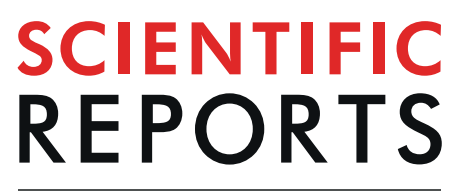

natureresearch

\title{
Incorporation of humic acid into biomass derived carbon for enhanced adsorption of phenol
}

\author{
Min Song ${ }^{1 *}$, Bing Song ${ }^{1}$, Fanyue Meng ${ }^{1}$, Dandan Chen $^{1,2}{ }^{2}$, Fei Sun ${ }^{1}$ \& Yuexing Wei ${ }^{1}$
}

In the present work, the biomass derived carbon decorated with humic acid (HC), was synthesized through impregnation method for the adsorption of phenol from water environment. Humic acids contain more oxygen-containing functional groups and hydrogen bonds, which promotes the binding between $\mathrm{HC}$ and phenol molecules. The results indicated that the adsorption performance of $\mathrm{HC}$ to phenol was better than that of commercial activated carbon. Moreover, in addition to physical absorption, the chemical reaction between carboxylic groups on the carbon surface and hydroxyl in phenol also played an important role during the process. The adsorption behavior of $\mathrm{HC}$ was described by equilibrium and kinetics parameters. Pseudo-second order model can describe the adsorption process well. Langmuir model was more suitable for the equilibrium adsorption data fitting, indicating that the adsorption mechanism of phenol on carbon surface tends to be monolayer adsorption. Considering practical application, $\mathrm{UV}_{254}$, chemical oxygen demand (COD) and ammonia from raw wastewater were selected as target contaminants and the corresponding adsorption experiments were carried out. The results displayed that $\mathrm{HC}$ exhibited excellent adsorption performance, especially for $\mathrm{UV}_{254}$ indicating that as-prepared carbon material had potential application for the control of certain organic pollutants in actual wastewater.

Activated carbon $(\mathrm{AC})$ has received increasing attention in the past several decades due to its excellent properties such as large surface area, thermal stability, and rich surface functional groups ${ }^{1,2}$. With the excellent texture and surface properties, AC is a suitable material for adsorption treatment of some organic compounds in wastewater. However, the practical application of AC in wastewater treatment is limited by its high cost ${ }^{3,4}$. Therefore, recently, a large amount of researches focused on the development of AC derived from various carbonaceous materials such as biomass and solid wastes ${ }^{5,6}$. The synthesis of AC from rice husk and sawdust has drawn large attention in China due to their high carbon content and huge reserves. Mohammed et al. ${ }^{7}$ prepared activated carbon using Acacia mangium wood as raw material and the influence of chemical agents as well as activation atmosphere on the morphology of the formed carbons were investigated. Rhodamine $\mathrm{B}(\mathrm{Rh} \mathrm{B})$ and methylene blue $(\mathrm{MB})$ dyes were selected as target pollutants to estimate its adsorption activity. The results indicated that AC treated by $\mathrm{H}_{3} \mathrm{PO}_{4}$ was possessed of good adsorption performance for $\mathrm{Rh} \mathrm{B}$ and $\mathrm{MB}$. Liu et al. synthesized a bamboo-based $\mathrm{AC}$ by using microwave-induced activation with $\mathrm{H}_{3} \mathrm{PO}_{4}$ as activating agent ${ }^{8}$. The surface area of bamboo-based carbon was $1432 \mathrm{~m}^{2} / \mathrm{g}$ and its pore structure was developed, which was expected to be widely used as a good adsorbent. In addition, activated carbons with good physical and chemical properties were also prepared by chitosan $^{9}$, sugarcane bagasse ${ }^{10}$, Jatropha hull ${ }^{11}$ and other biomass materials ${ }^{12,13}$. However, biomass derived carbon also had its inherent disadvantages. One of the most obvious defects was that there were fewer functional groups on the surface of carbon, which significantly limited its adsorption performance for the removal of organic matters in water ${ }^{14,15}$. Therefore, the surface characteristic of biomass derived carbons need to be improved by modification.

In recent years, humic acid (HA) has been widely used as adsorbent to remove pollutants in water ${ }^{16-18}$. There are two advantages for the utilization of HA. On the one hand, it could be extracted from brown coal, soil, peat and lake, so the cost of HA is low. On the other hand, HA molecule contained abundant functional groups, such as hydroxyl group, alcoholic hydroxyl group, phenolicydrazine-type carbonyl group and ketone-type carbonyl group. These groups can interact with metal ions, oxides, hydroxides, minerals, organic matters and toxic

${ }^{1}$ Key Laboratory of Energy Thermal Conversion and Control of Ministry of Education, School of Energy and Environment, Southeast University, Nanjing, Jiangsu, 210096, China. ${ }^{2}$ School of Energy \& Mechanical Engineering, Nanjing Normal University, Nanjing, Jiangsu, 210023, China. *email: minsong@seu.edu.cn 


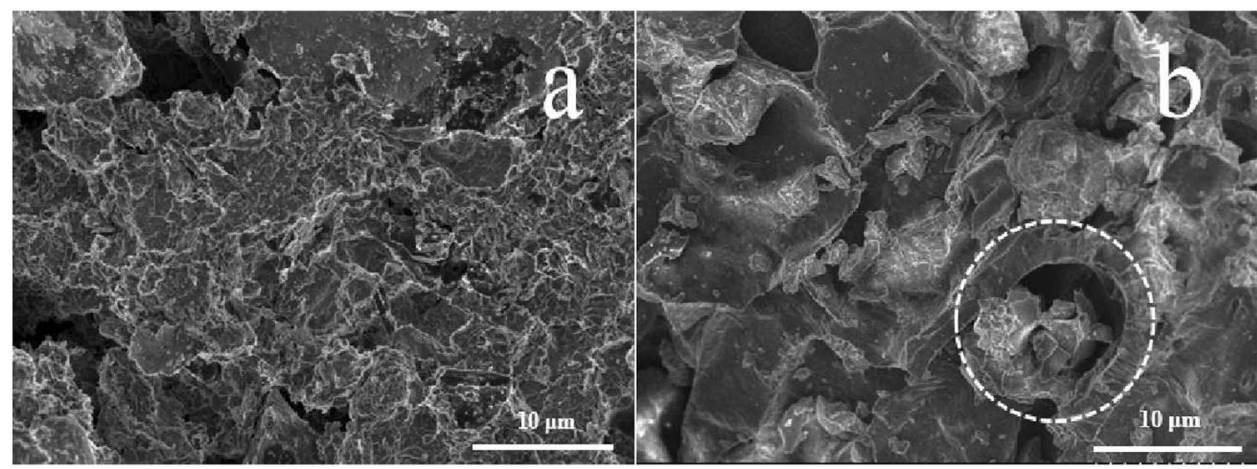

Figure 1. SEM photographs of (a) RC and (b) HC.

\begin{tabular}{|l|c|l|l|l|l|}
\hline Samples & $\mathbf{S}_{\text {BET }}\left(\mathbf{m}^{2} / \mathbf{g}\right)$ & $\mathbf{S}_{\text {mic }}\left(\mathbf{m}^{2} / \mathbf{g}\right)$ & $\mathbf{V}_{\text {mic }}\left(\mathrm{cm}^{3} / \mathbf{g}\right)$ & $\mathbf{V}_{\mathbf{t}}\left(\mathbf{c m}^{3} / \mathbf{g}\right)$ & $\mathbf{D}_{\mathbf{p}}(\mathbf{n m})$ \\
\hline RC & 1196.79 & 682.49 & 0.3037 & 0.7362 & 2.46 \\
\hline HC & 681.47 & 340.25 & 0.1488 & 0.4781 & 2.81 \\
\hline Humic acid & 1.17 & - & - & 0.0858 & 2.94 \\
\hline
\end{tabular}

Table 1. Structural parameters of various samples. Note: $S_{\mathrm{BET}}$ : Brunauer-Emmett-Teller surface area; $\mathrm{S}_{\text {mic }}$ : micropores surface area; $\mathrm{V}_{\text {mic }}:$ micropores volume; $\mathrm{V}_{\mathrm{t}}$ : total pore volume; $\mathrm{D}_{\mathrm{p}}$ : average pore diameter.

active pollutants in the environment, which can improve the hydrophilicity, adsorption and complexation of HA. Previous studies have shown that humic substances had potential application prospects for solid adsorbent modification for the remediation of contaminated water. Radwan et al. ${ }^{19}$ proposed a novel humic acid-carbon hybrid material with excellent adsorption capacity toward phenol due to its larger surface area and abundant oxygen-containing functional groups on the surface of carbon. Moreover, the novel material could be employed under a wide range of environmental conditions. Vinod et al. ${ }^{20}$ studied the adsorption performance of humic acid immobilized pillared clay (HA-PILC) for $\mathrm{MB}$, crystal violet (CV), and $\mathrm{Rh} \mathrm{B}$. The results demonstrated that HA-PILC was an excellent media for cleaning treatment of organic matters in water environment.

In this study, humic acid is selected and loaded on the activated carbon from rice husk. The surface properties of activated carbon were modified and functional groups were introduced to carbon surface. Phenol in industrial wastewater is selected as target contaminant. The adsorption performance of as-prepared samples to typical organic pollutants was tested. The effect of contact time, temperature, and $\mathrm{pH}$ were studied. Moreover, the adsorption isotherm and kinetic were also investigated in this study, which can offer available information for optimizing treatment process of organic pollutants from wastewater.

\section{Results and Discussion}

Morphological properties. SEM photographs of rice husk-carbon (RC) and humic acid-carbon (HC) were recorded in Fig. 1. Based on Fig. 1(a), a good deal of mesopores was distributed irregularly on the RC surface, which provided a large specific surface area for the contact and adsorption of organic pollutants. The pore structure of biomass derived carbon modified by humic acid (HA) was developed, whereas partial pores were blocked (Fig. 1(b)), leading to the reduction of available surface and active sites.

The structural parameters of original and modified carbon were both listed in Table 1 and Figs. S1, S2. It can be clearly observed that RC was possessed of a high surface area of $1196.79 \mathrm{~m}^{2} / \mathrm{g}$ and a large pore volume of $0.3037 \mathrm{~cm}^{3} / \mathrm{g}$. However, the pore structure of HA was poor, with a specific surface area of only $1.17 \mathrm{~m}^{2} / \mathrm{g}$ and its pore volume was too small to be detected. Although the proportion of RC in the modified sample was only $50 \%$, but as prepared adsorbent, HC, still had considerable specific surface area of $681.47 \mathrm{~m}^{2} / \mathrm{g}$. Furthermore, for HC prepared through recombination of $\mathrm{HA}$ and $\mathrm{RC}$ with a mass ratio of 1:1, it was interesting that its specific surface area did not decrease proportionately with its composition as expected, but was greater than the sum of that of them $\left(598.98 \mathrm{~m}^{2} / \mathrm{g}\right)$. This is because ultrasonic treatment of the sample during preparation, which helps to remove impurities distributed on carbon surfaces or in channels, thus increasing the specific surface area of the sample.

Static adsorption. Adsorption time is an important factor affecting the adsorption of phenol from solution by carbon based composite, as demonstrated in Fig. 2. The initial concentration of phenol was $40 \mathrm{mg} / \mathrm{L}$. Because of its excellent textural properties, RC exhibited the best adsorption performance to phenol. The adsorption capacity of $\mathrm{HC}$ was slightly inferior than RC, but it also significantly exceeded that of commercial activated carbon (CAC) and HA. Moreover, the adsorption rate of adsorbents also varied. The adsorption amounts of RC and $\mathrm{HC}$ for phenol increased sharply in the first $20 \mathrm{~min}$ and arrived at equilibrium after $30 \mathrm{~min}$. The adsorption rate of CAC was slower than that of RC and $\mathrm{HC}$ and it reached equilibrium after $90 \mathrm{~min}$. Interestingly, the adsorption capacity of HA was rather poor, but its adsorption rate was the fastest among the four adsorbents and it reached adsorption saturation within less than $10 \mathrm{~min}$. The results demonstrated that compared to CAC, HC required less residence time and presented more excellent adsorption property for organic pollutants in water environment. 


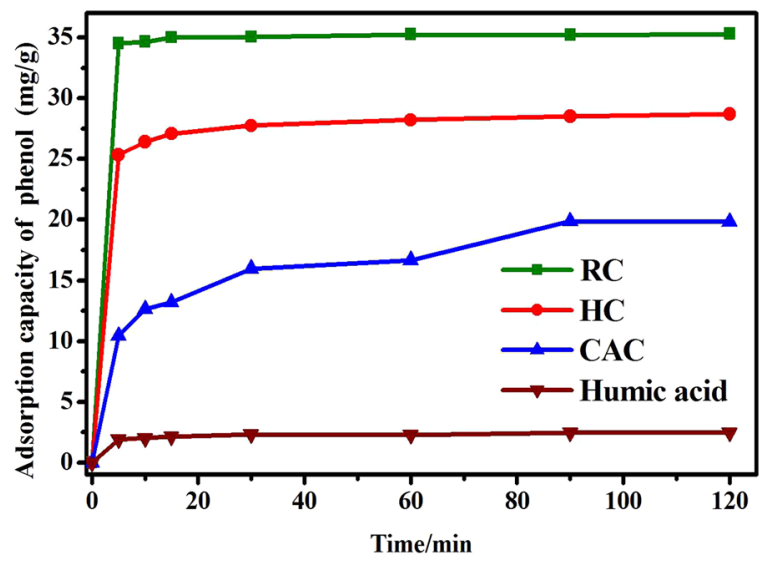

Figure 2. The adsorption performance of various samples for phenol with adsorption time.

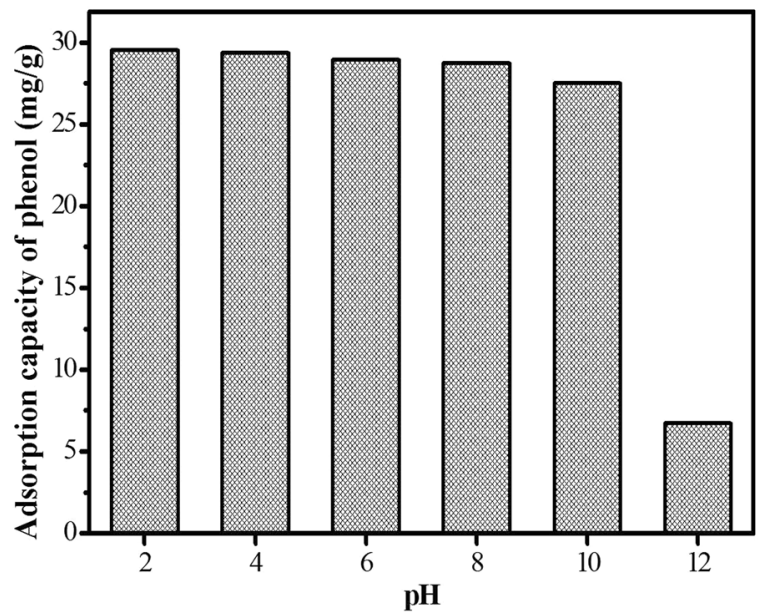

Figure 3. Effect of $\mathrm{pH}$ on the removal of phenol.

Additionally, for the composite adsorbent comprised of RC and HA at the rate of 1:1 in mass, its adsorption capacity was not less than half of that of RC, but reached $80.88 \%$ of that of the latter. It might be attributed to the following reasons: (i) developed pore structure; (ii) uniform distribution of HA with abundant oxygen-containing functional group on carbon surface. The hydrogen bond between oxygen in phenol molecules and hydrogen in oxygen-containing functional groups could be formed and facilitate the combination between adsorbate and adsorbent, resulting in a good adsorption capacity. Despite that adsorption capacity of HC was not extremely desirable, but it had fairly low cost compared to RC and CAC. Therefore, the as prepared carbon decorated with HA had great potential on adsorption treatment of phenol from water environment.

Effects of pH. The removal of phenol versus $\mathrm{pH}$ was recorded in Fig. 3. The adsorption performance of HC decreased with $\mathrm{pH}$. At acidic conditions, the adsorption capacity of $\mathrm{HC}$ was almost unchanged, and decreased rapidly when $\mathrm{pH}$ was greater than 10 . It could be assigned to the variation of surface charge on the adsorbent and the solubleness of adsorbate at different solution $\mathrm{pH}^{21,22}$. As a weak $\operatorname{acid}^{23}$, phenol was dissociated when $\mathrm{pH}>\mathrm{pK}_{\mathrm{a}}$ and was transformed into phenolate-phenolate anions at alkaline $\mathrm{pH}$ due to the ionization of phenol molecules. Therefore, the reason for the decrease of adsorption amount might be assigned to electrostatic repulsions between negative surface charges caused by $\mathrm{OH}^{-}$at high $\mathrm{pH}$ and the phenolate anions ${ }^{24}$. While in acidic environment, the adsorption capacity remained almost unchanged because phenol was undissociated and dispersion interaction predominated.

Adsorption kinetics. To better illustrate the adsorption behavior of phenol on HC surface, pseudo-first-order kinetics model and pseudo-second-order kinetics model were used to fit the data. The former model assumed that adsorbate molecules were proportionally bound to the active sites, whereas in the latter model adsorbate molecule was adsorbed onto two active sites ${ }^{25}$. According to Trivedi ${ }^{26}$ and Ho (Mckay) ${ }^{27}$, the equations of the two kinetic models were given as:

$$
q t=q e(1-\exp (-k 1 t))
$$




\begin{tabular}{|l|l|l|l|l|l|l|l|}
\hline \multirow{2}{*}{ Absorbate } & \multirow{2}{*}{ Adsorbent } & \multicolumn{4}{|l|}{ Pseudo-first order } & \multicolumn{4}{l|}{ Pseudo-seconder } \\
\cline { 3 - 8 } & $\left.\mathbf{q}_{\mathbf{e}} \mathbf{( m g} / \mathbf{g}\right)$ & $\mathbf{k}_{\mathbf{1}}\left(\mathbf{g}(\mathbf{m g} / \mathbf{m i n})^{-\mathbf{1}}\right.$ & $\mathbf{R}^{\mathbf{2}}$ & $\mathbf{q}_{\mathbf{e}}(\mathbf{m g} / \mathbf{g})$ & $\mathbf{k}_{\mathbf{2}}\left(\mathbf{g}(\mathbf{m g} / \mathbf{m i n})^{-\mathbf{1}}\right.$ & $\mathbf{R}^{\mathbf{2}}$ \\
\hline phenol & HC & 72.94 & 0.546 & 0.79 & 17.28 & 8.74 & 0.996 \\
\hline
\end{tabular}

Table 2. Kinetics parameters for phenol adsorption.

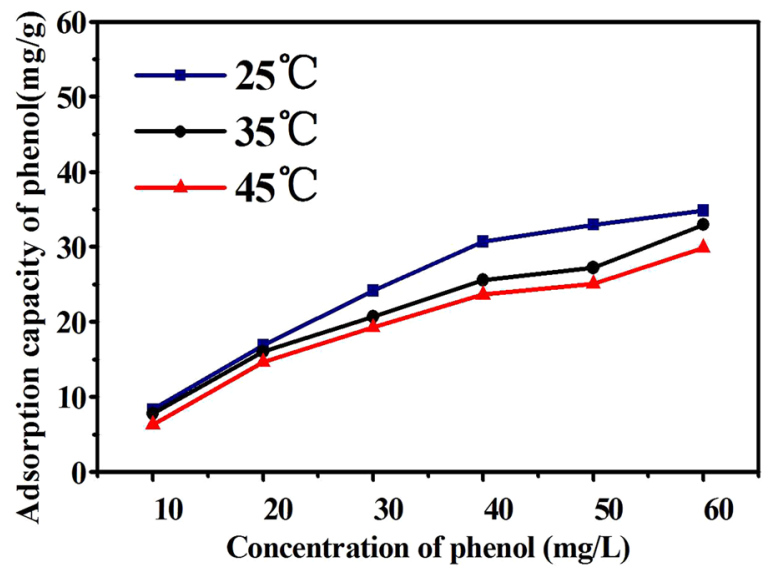

Figure 4. Adsorption isotherms of phenol on HC.

$$
\frac{t}{q t}=\frac{1}{k 2 q_{e} \cdot q_{e}}+\frac{t}{q e}
$$

where $q_{\mathrm{e}}(\mathrm{mg} / \mathrm{g})$ is adsorption capacity of adsorbent at equilibrium, $k_{1}\left(\mathrm{~min}^{-1}\right)$ and $k_{2}(\mathrm{mg} / \mathrm{g} \bullet \mathrm{min})$ are rate constants, $t$ ( $\mathrm{min})$ is adsorption time.

The kinetics parameters calculated through the equations were recorded in Table 2 . The correlation coefficients $\left(\mathrm{R}^{2}\right)$ and $\mathrm{q}_{\mathrm{e}}$ were utilized to confirm the suitability of two models. The $\mathrm{R}^{2}$ value of pseudo first order kinetics model was fairly low, whereas that of pseudo second order model was larger than 0.99 . The calculated equilibrium adsorption capacity was also accorded with actual adsorption capacity of as prepared adsorbent according to pseudo-second-order model, which demonstrates that this model could better depict the adsorption behavior.

Adsorption isotherm. The adsorption was performed at various temperatures with various initial concentrations of organic compounds from $10 \mathrm{mg} / \mathrm{L}$ to $60 \mathrm{mg} / \mathrm{L}$. The impact of temperature on migration and adsorption behavior of phenol on HC surface were demonstrated in Fig. 4. On the one hand, the absorption capacity of adsorbent for phenol decreased to varying degrees with the increase of temperature and initial concentration. It could be inferred that the adsorption reaction was an exothermic process, the interaction between adsorbent and organic compound (i.e. electrostatic force and hydrogen bond) decreased with increasing temperature, resulting in a decrease in adsorption capacity. On the other hand, the average pore size of HC was $2.81 \mathrm{~nm}$ (see Table 1), which was bigger than the kinetic diameter of phenol. The larger pore was conducive to accelerate the adsorption rate and aggravate the intra-particle diffusion. Additionally, the growth rate of adsorption capacity decreased gradually with increasing initial concentration. This is mainly because the diffusion resistance of the organic compound would increase in gradually the narrow pores with the increasing concentration of pollutant.

Furthermore, the adsorption of $\mathrm{HC}$ to phenol decreased with the increasing temperature, which demonstrates that there was chemical interaction between adsorbate and oxygen-containing functional groups ${ }^{28}$. Thus, to clarify the interaction and figure out the binding mechanism between the adsorbent and phenol, FTIR, Boehm titration, and XPS were applied. Based on Fig. 5(A), the peaks at 1040 and $1625 \mathrm{~cm}^{-1}$ were respectively assigned to $\mathrm{C}-\mathrm{O}$ and $\mathrm{C}=\mathrm{C}$ stretching. The band at $3450 \mathrm{~cm}^{-1}$ was referred to $\mathrm{OH}$ stretching of $\mathrm{H}$-bonded water and it was unchanged before and after adsorption. Additionally, the relative strength of the peak assigned to carboxylic acid groups $\left(1750 \mathrm{~cm}^{-1}\right)$ decreased after adsorption, whereas the relative strength of ester groups $\left(1382 \mathrm{~cm}^{-1}\right)$ increased. This is also consistent with the data in Table S1. It could be inferred that, in addition to physical absorption, the chemical reaction between carboxylic groups on the carbon surface and hydroxyl in phenol also played a role in the removal process of phenol from aqueous solution by the modified carbon. Furthermore, based on the interpolation table of Fig. 5(A), more hydroxyl groups, lactone groups and phenol hydroxyl groups on the $\mathrm{HC}$ surface were observed compared to that on the RC surface. These groups were derived from HA which contains rich acidic functional groups. The increase of functional groups might be beneficial to enhance the adsorption performance of HC to phenol. The XPS spectra of O $1 \mathrm{~s}$ of samples before and after adsorption were shown in Fig. 5(B). The absorption peak appearing in the range of 540 to $528 \mathrm{eV}$ was corresponded to $\mathrm{O}$ $1 \mathrm{~s}$. It could be clearly observed that $\mathrm{O} 1 \mathrm{~s}$ peak was deconvoluted into five Gaussian symmetric curves at 531.7, $532.8,533.9,534.8$, and $536.8 \mathrm{eV}$. The corresponding details of these peaks were listed in the interpolation table of 

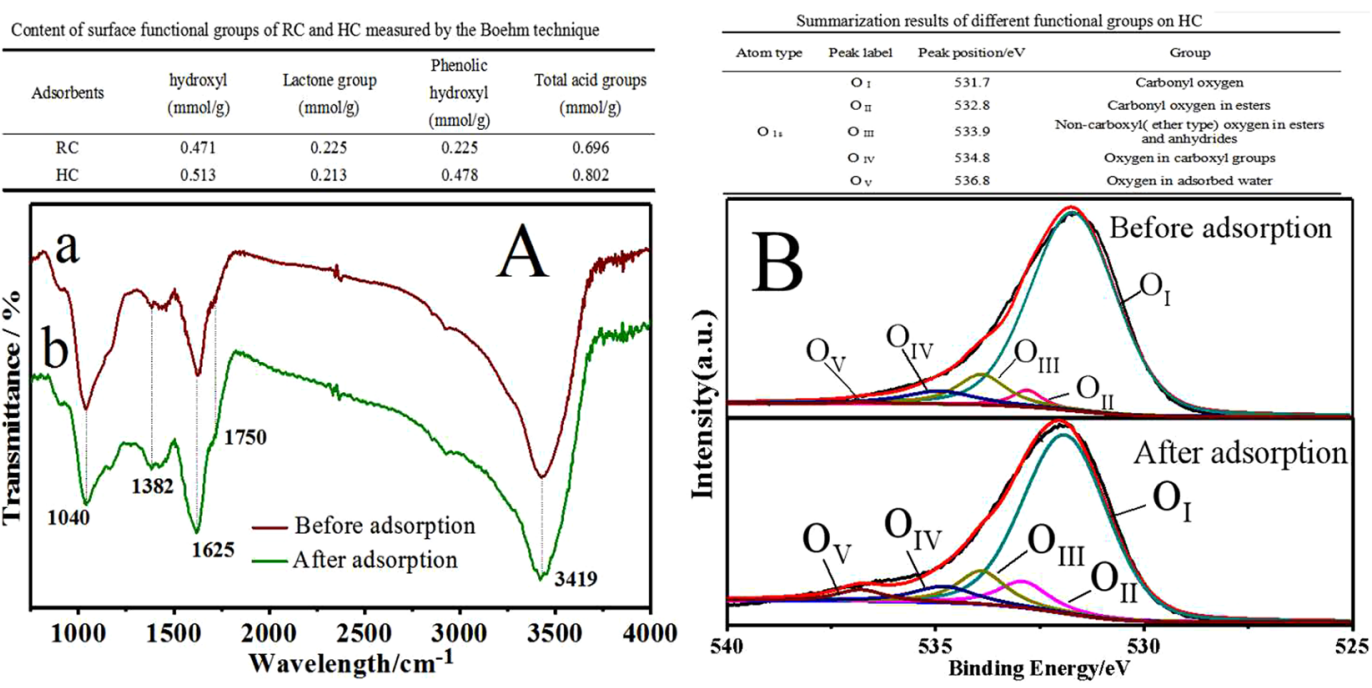

Figure 5. Typical FTIR spectra (A) and XPS (B) of the starting and tested adsorbents.

\begin{tabular}{|l|l|l|l|l|l|l|l|}
\hline \multirow{2}{*}{ Absorbate } & \multirow{4}{*}{ Adsorbent } & \multicolumn{4}{|l|}{ Langmuir model } & \multicolumn{4}{l|}{ Freundlich model } \\
\cline { 3 - 9 } & $\mathbf{q}_{\mathbf{m}}(\mathbf{m g} / \mathbf{g})$ & $\mathbf{K}_{\mathbf{L}}(\mathbf{L} / \mathbf{m g})$ & $\mathbf{R}^{\mathbf{2}}$ & $\mathbf{K}_{\mathbf{F}}(\mathbf{L} / \mathbf{g})$ & $\mathbf{1} / \mathbf{n}$ & $\mathbf{R}^{\mathbf{2}}$ \\
\hline Phenol & HC & 58.89 & 0.105 & 0.9848 & 8.649 & 0.49 & 0.9167 \\
\hline
\end{tabular}

Table 3. Isotherm parameters for HC.

Fig. 5(B). The peak area corresponding to ester group was significantly increased, demonstrating the increase of ester groups in $\mathrm{HC}$ after adsorption. The result indicated that new ester groups were formed during the adsorption process which was in good agreement with the FTIR data.

In order to predict the modelling procedures, the data derived from the adsorption experiment of $\mathrm{HC}$ to phenol were fitted by the Langmuir and Freundlich isotherm models. According to Langmuir ${ }^{29}$ and Hameed $^{30}$, the linear formulas of Langmuir and Freundlich model were described as:

$$
\begin{aligned}
& \frac{1}{q e}=\frac{1}{k_{1} q m} * \frac{1}{C e}+\frac{1}{q m} \\
& \ln q e=\ln k_{2}+\frac{1}{n} \ln C e
\end{aligned}
$$

where $q_{\mathrm{e}}(\mathrm{mg} / \mathrm{g})$ is adsorption capacity of adsorbent at equilibrium, $q_{\mathrm{m}}$ is theoretical monolayer adsorption capacity, $C_{\mathrm{e}}$ is equilibrium concentration of adsorbing, $k_{1}, k_{2}$ and $1 / n$ are adsorption constants.

The parameters corresponding to the Langmuir and Freundlich model were listed in Table 3 . The results showed that the adsorption performance of phenol was better fitted by the first model. It could be deduced that the adsorption behavior of the organic pollutant on $\mathrm{HC}$ surface was inclined to follow monolayer adsorption mechanism. Furthermore, the values of $1 / n$ were arranged from 0.49 to 0.71 , which implied favorable adsorption for phenol on the carbon surface.

Table 4 enumerated the maximum adsorption capacities of different carbon based adsorbents to phenol, which were derived from corresponding literatures. It can be concluded that the carbon based adsorbent investigated in this work had excellent adsorption performance to the organic pollutant in aqueous solution.

Adsorption of actual wastewater. In order to further investigate practical application on the removal of organic compounds, $\mathrm{HC}$ and commercial activated carbon (CAC) were selected as adsorbents for the adsorption experiments to certain organic pollutants from actual wastewater. Concentrations of the pollutants could reflect the content of macromolecular organic matters and the aromatic compounds containing $\mathrm{C}=\mathrm{C}$ double bond or $\mathrm{C}=\mathrm{O}$ double bond present in water. Therefore, ammonia, $\mathrm{COD}$, and $\mathrm{UV}_{254}$ were chosen as target contaminants in the work to evaluate the ability of adsorbents to remove organic pollutants in wastewater. The adsorption experiments were performed based on the same experiment procedures (as described in Section 2.5) and the result was shown in Fig. 6. It was clearly observed that as prepared sample displayed favourable removal efficiency for ammonia, $\mathrm{COD}$, and $\mathrm{UV}_{254}$. Moreover, its performance was apparently superior to commercial activated carbon. The COD concentration was reduced from $212 \mathrm{mg} / \mathrm{g}$ of the original wastewater to less than $5 \mathrm{mg} / \mathrm{L}$ of the treated wastewater which was far below the sewage discharge standard value (GB8978-1996) (Table S2), and the removal rate reached $99.52 \%$. The above results indicated that the as prepared carbon based materials have potential application prospects in practical wastewater treatment. 


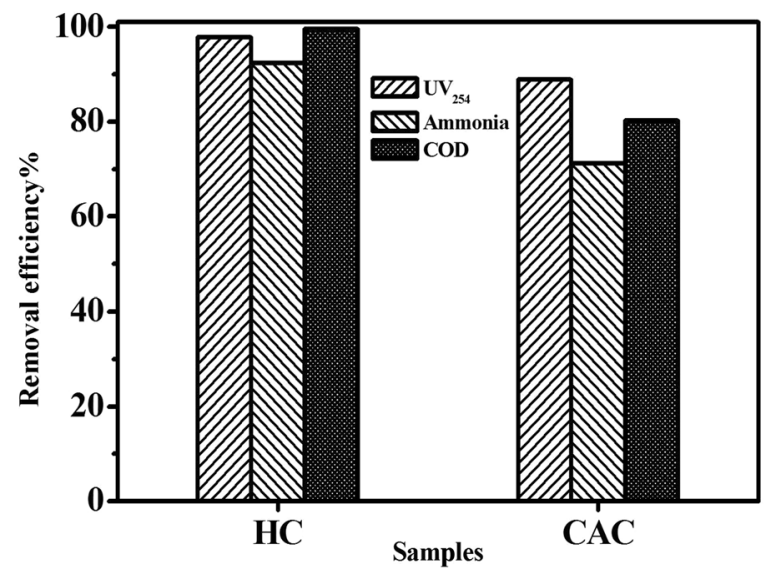

Figure 6. The removal rate of UV254, ammonia, and COD in practical wastewater by different adsorbents.

\begin{tabular}{|c|c|c|c|c|c|c|c|c|}
\hline \multirow[b]{3}{*}{ Adsorbents } & \multirow[b]{3}{*}{ Adsorbate } & \multicolumn{6}{|c|}{ Isotherm model } & \multirow[b]{3}{*}{ References } \\
\hline & & \multicolumn{3}{|c|}{ Langmuir model } & \multicolumn{3}{|c|}{ Freundlich model } & \\
\hline & & $\mathrm{q}_{\mathrm{m}}, \mathrm{mg} / \mathrm{g}$ & $\mathrm{K}_{\mathrm{L}}, \mathrm{L} / \mathbf{m g}$ & $\mathbf{R}^{2}$ & $\mathbf{n}$ & $\mathrm{K}_{\mathrm{F}}$ & $\mathbf{R}^{2}$ & \\
\hline $1.2 \mathrm{SEP} / \mathrm{C}$ & Phenol & 5.26 & 0.0265 & 0.993 & 1.54 & 0.21 & 0.950 & 31 \\
\hline Bentonite (surfactant) & Phenol & 22.88 & 0.011 & 0.996 & 31.8 & 3.4 & 0.958 & 32 \\
\hline Granular activated carbon & Phenol & 112.36 & 0.013 & 0.996 & 1.28 & 3.03 & 0.981 & 33 \\
\hline Amine-modified activated carbon & Phenol & 18.12 & 0.000059 & 0.999 & 3.11 & 0.39 & 0.983 & 34 \\
\hline MWCNTs & Phenol & 32.25 & 3.17 & 0.990 & 1.76 & 1.11 & 0.896 & 35 \\
\hline $\mathrm{HC}$ & Phenol & 58.89 & 0.1050 & 0.984 & 2.02 & 8.64 & 0.917 & This work \\
\hline
\end{tabular}

Table 4. Comparison of organic pollutant removal by various adsorbents.

\begin{tabular}{|l|l|l|l|l|l|l|l|l|}
\hline \multirow{3}{*}{ Material } & \multicolumn{4}{|l|}{ Elemental analysis/\% } & \multicolumn{4}{l|}{ Industrial analysis /\% } \\
\cline { 2 - 10 } & $\mathbf{C}_{\text {ad }}$ & $\mathbf{H}_{\text {ad }}$ & $\mathbf{N}_{\text {ad }}$ & $\mathbf{O}_{\text {ad }}$ & $\mathbf{V}_{\text {ad }}$ & $\mathbf{F C}_{\text {ad }}$ & $\mathbf{A}_{\mathbf{d}}$ & $\mathbf{M}_{\text {ad }}$ \\
\hline Rice husk & 50.07 & 6.07 & 0.63 & 43.23 & 67.28 & 11.61 & 12.92 & 8.18 \\
\hline
\end{tabular}

Table 5. Elemental analysis and industrial analysis of rice husk. Note: Ad: air dried basis; d: dried basis

In conclusion, this study exhibited the potential of the rice husk-based carbon coated with humic acid for phenol removal from aqueous solution. HC was possessed of high surface area and abundant oxygen-containing functional groups, and it exhibited excellent adsorption performance for phenol. The optimum removal condition of $\mathrm{HC}$ was attained at $\mathrm{pH}=6,25^{\circ} \mathrm{C}$ and $30 \mathrm{~min}$ contact time. The experimental data derived from the adsorption process of the carbon based adsorbent for phenol was best fitted by the Langmuir adsorption isotherm model. The kinetic results demonstrated that the process was better described through pseudo second-order model. Based on the adsorption results of $\mathrm{COD}, \mathrm{UV}_{254}$, and ammonia from raw water, it could be concluded that as prepared carbon based materials can be employed as highly efficient adsorbents used for the disposal of organic pollutants in practical wastewater.

\section{Methods}

Rice husk was obtained from Shandong, China. Hydrochloric acid $(\mathrm{HCl})$, potassium hydroxide $(\mathrm{KOH})$, phenol was all provided by Sigma-Aldrich. The elemental analysis and industrial analysis for rice husk were shown in Table 5. It can be inferred that the raw material is in rich of carbon element and is suitable for the synthesis of activated carbon. Phenol used in this study was analytically pure grade and its main properties were shown in Table $6^{36,37}$.

Preparation of biomass derived carbon. After pretreatment, a certain amount of rice husk was mixed with $\mathrm{KOH}$ solution at $\mathrm{KOH} /$ rice husk weight ratio of 3:1 in a glass beaker. The mixture was stirred at $40^{\circ} \mathrm{C}$ for $8 \mathrm{~h}$, and was then dried in the oven at $105^{\circ} \mathrm{C}$ for $24 \mathrm{~h}$. The activated sample were transferred to a quartz boat and placed in a high temperature horizontal tube furnace. Under the $\mathrm{N}_{2}$ flow condition, the temperature was set at $800^{\circ} \mathrm{C}$ and the samples were held at this condition for $60 \mathrm{~min}$. Finally, the product was washed with $0.05 \mathrm{~mol} / \mathrm{L}$ hydrochloric solution until the filtrate was neutral and was then dried in the air dry oven at $105^{\circ} \mathrm{C}$ for $24 \mathrm{~h}$. The obtained final product was named as rice husk-carbon (labeled as RC). 


\begin{tabular}{|l|l|l|l|l|l|l|l|l|l|l|}
\hline Adsorbate & $\mathbf{M W}$ & $\mathbf{C}_{\mathbf{s}}$ & $\mathbf{L}_{\max }$ & $\mathbf{p K}_{\mathbf{a}}$ & $\square^{*}$ & $\left\langle_{\mathrm{m}}\right.$ & ${ }^{\circledR}{ }_{\mathbf{m}}$ & $\mathbf{d}_{\mathbf{m}}$ & \rangle & $\mathbf{M P}$ \\
\hline phenol & 94.11 & 80190 & 269 & 9.9 & 0.72 & 0.61 & 0.33 & 0.69 & 1.071 & 40.9 \\
\hline
\end{tabular}

Table 6. Selected physicochemical properties of the adsorbate ${ }^{\mathrm{a}}$. Note: ${ }^{\mathrm{a}} \mathrm{MW}$ : molecular weight (g/mol); $\mathrm{C}_{\mathrm{s}}$ : water solubility $(\mathrm{mg} / \mathrm{L})($ at $298 \mathrm{~K}) ; \lambda_{\max }$ : maximum adsorption wavelength $(\mathrm{nm}) ; \mathrm{pK}_{\mathrm{a}}$ : dissociated constant (at $298 \mathrm{~K}) ; \pi^{*}$ : polarity/polarizability parameter; $\alpha_{\mathrm{m}}$ : hydrogen-bonding donor parameter; $\beta_{\mathrm{m}}$ : hydrogen-bonding acceptor parameter; $\mathrm{d}_{\mathrm{m}}$ : molecular dynamics diameter $(\mathrm{nm}) ; \rho:$ density $\left(\mathrm{g} / \mathrm{cm}^{3}\right)$; MP: melting points $\left({ }^{\circ} \mathrm{C}\right)$.

Preparation of carbon based composite adsorbents. Humic acid was mixed with RC at weight ratio of 1:1. A small amount of distilled water was put into the mixture and the $\mathrm{pH}$ value of solution was regulated to 2 with hydrochloric solution $(1 \mathrm{~mol} / \mathrm{L})$. The solution was slowly stirred by a glass rod for $15 \mathrm{~min}$, ultrasonicated for $30 \mathrm{~min}$, then washed, filtered and dried. The obtained composite material, humic acid-carbon, was designated as HC.

Characterization of carbon based composite adsorbents. The porous texture of synthesized adsorbents was characterized through Surface Area and porosimetry Analyzer (V-Sorb 2800 P). The species and quantity of functional groups on carbon surface were investigated by Boehm titration method ${ }^{15,38}$. The microstructure of adsorbents was imaged using a scanning electron microscopy (SEM) (Hitachi, S-3000N), operating at a $20 \mathrm{kV}$ accelerating voltage. The functional groups on samples surface were also characterized by a Fourier transform infrared spectra (Bruker Tensor 27, Germany) in the scanning region of $500-4000 \mathrm{~cm}^{-1}$. The nature of chemical binding of samples was identified by XPS (VG Scienta, USA).

Batch adsorption experiments. In the experiment, phenol was selected as the targeted contaminant. $100 \mathrm{~mL}$ phenol $(40 \mathrm{mg} / \mathrm{L})$ and as prepared adsorbents $(0.1 \mathrm{~g})$ were transferred to glass bottles. The glass bottles were mechanically shaken $(150 \mathrm{rpm})$ at room temperature in a constant temperature oscillator (KYC-1102C). The concentration of phenol after filtering was then measured. The formula for equilibrium adsorption capacity was defined as follows:

$$
q e=\frac{V 0(C 0-C e)}{m}
$$

where, $q_{\mathrm{e}}$ is equilibrium absorption capacity of samples $(\mathrm{mg} / \mathrm{g}) ; V_{0}$ represents solution volume $(\mathrm{ml}) ; C_{0}$ and $C_{\mathrm{e}}$ are the concentrations of phenol at initial condition and at adsorption equilibrium condition $(\mathrm{mg} / \mathrm{L})$, respectively; $m$ is the mass of adsorbent ( $\mathrm{g}$ ). For comparison, commercial activated carbons (CAC), humic acid, and RC were all used in adsorption experiments.

\section{Data availability}

All data generated or analysed during this study are included in this article.

Received: 30 September 2019; Accepted: 11 December 2019;

Published online: 27 December 2019

\section{References}

1. Chu, L. L. et al. Adsorption/desorption performance of volatile organic compounds on electrospun nanofibers. Rsc $A d v . \mathbf{5}$, 102625-102632 (2015).

2. Huang, S. \& Liang, C. A conceptual study on the formulation of a permeable reactive pavement with activated carbon additives for controlling the fate of non-point source environmental organic contaminants. Chemosphere. 193, 438-446 (2017).

3. Zhang, X., Gao, B., Creamer, A. E., Cao, C. C. \& Li, Y. C. Adsorption of VOCs onto engineered carbon materials: A review. J. Hazard. Mater. 338, 102-123 (2017).

4. Wang, H. et al. Adsorption and desorption of mixtures of organic vapors on beaded activated carbon. Environ. Sci. Technol. 46, 8341-8350 (2012).

5. Xu, G. Y. et al. Biomass-derived porous carbon materials with sulfur and nitrogen dual-doping for energy storage. Green Chem. 17, 1668-1674 (2015).

6. Singh, G., Lakhi, S., Ramadass, K., Sathish, K. \& Vinu, C. A. High-performance biomass-derived activated porous biocarbons for combined pre- and post-combustion $\mathrm{CO}_{2}$ capture. ACS Sust. Chem. Eng. 7, 7412-7420 (2019).

7. Danish, M. et al. Comparison of surface properties of wood biomass activated carbons and their application against rhodamine $B$ and methylene blue dye. Surf. Interfaces. 11, 1-13 (2018).

8. Liu, Q. S., Zheng, T., Wang, P. \& Guo, L. Preparation and characterization of activated carbon from bamboo by microwave-induced phosphoric acid activation. Ind. Crop. Prod. 2, 233-238 (2010).

9. Guo, M. et al. Carbon nanotube-grafted chitosan and its adsorption capacity for phenol in aqueous solution. Sci. Total. Environ. 682, 340-347 (2019).

10. Gonçalves, C. et al. Activated carbon from pyrolysed sugarcane bagasse: Silver nanoparticle modification and ecotoxicity assessment. Sci. Total. Environ. 565, 833-840 (2016).

11. Duan, X. H., Srinivasakannan, C., Peng, J. H., Zhang, L. B. \& Zhang, Z. Y. Comparison of activated carbon prepared from Jatropha hull by conventional heating and microwave heating. Biomass Bioenerg 9, 3920-3926 (2011).

12. Song, M. et al. Study on adsorption properties and mechanism of $\mathrm{Pb}^{2+}$ with different carbon based adsorbents. Sci. Total. Environ. 618, 1416-1422 (2018).

13. Meng, F. Y., Song, M., Wei, Y. X. \& Wang, Y. L. The contribution of oxygen-containing functional groups to the gas-phase adsorption of volatile organic compounds with different polarities onto lignin-derived activated carbon fibers. Environ. Sci. Pollut. R. 7, 7195-7204 (2019).

14. Sun, J. T. et al. Biomass-derived nitrogen-doped porous carbons with tailored hierarchical porosity and high specific surface area for high energy and power density supercapacitors. Appl. Sur. Sci. Part A 427, 807-813 (2018).

15. Singh, G. S. et al. Oxygen-functionalized mesoporous activated carbons derived from casein and their superior $\mathrm{CO}_{2}$ adsorption capacity at both low- and high-pressure regimes. ACS Appl. Nano Mater. 2, 1604-1613 (2019).

16. Tang, Z. et al. Characteristic and mechanism of sorption and desorption of benzene on humic acid. Environ. Sci. Pollut. R. 20, 20277-20285 (2019). 
17. Yang, Y. J., Wang, B., Guo, X. J., Zou, C. W. \& Tan, X. D. Investigating adsorption performance of heavy metals onto humic acid from sludge using Fourier-transform infrared combined with two-dimensional correlation spectroscopy. Environ. Sci. Pollut. R. 10, 9842-9850 (2019).

18. Zhang, J. Molecular structure-reactivity correlations of humic acid and humin fractions from a typical black soil for hexavalent chromium reduction. Sci. Total. Environ. 2, 2975-2984 (2019).

19. Radwan, K. et al. A. Preparation and characterization of humic acid-carbon hybrid materials as adsorbents for organic micropollutants. Environ. Sci. Pollut. R. 16, 12035-12049 (2015).

20. Vinod, V. P. \& Anirudhan, T. S. Adsorption behaviour of basic dyes on the humic acid immobilized pillared clay. Water. Air. Soil. Poll. 1-4, 193-217 (2003).

21. Reddy, D. H. K. \& Lee, S. M. Application of magnetic chitosan composites for the removal of toxic metal and dyes from aqueous solutions. Adv. Colloid. Interfac. 201-202, 68-93 (2013).

22. Thinakaran, N., Baskaralingam, P., Pulikesi, M., Panneerselvam, P. \& Sivanesan, S. Removal of Acid Violet 17 from aqueous solutions by adsorption onto activated carbon prepared from sunflower seed hull. J. Hazard. Mater. 2-3, 316-322 (2008).

23. Aksu, Z. \& Kabasakal, E. Batch adsorption of 2,4-dichlorophenoxy-acetic acid (2,4-D) from aqueous solution by granular activated carbon. Sep. Purif. Technol. 3, 223-240 (2003).

24. Moreno-Castilla, C. Adsorption of organic molecules from aqueous solutions on carbon materials. Carbon 1, 83-94 (2004).

25. Subbaiah, M. V. \& Kim, D. S. Adsorption of methyl orange from aqueous solution by aminated pumpkin seed powder: Kinetics, isotherms, and thermodynamic studies. Ecotox. Environ. Safe. 128, 109-117 (2016).

26. Trivedi, H. C., Patel, V. M. \& Patel, R. D. Adsorption of cellulose triacetate on calcium silicate. Eur. Polym. J. 6, 525-531 (1973).

27. Ho, Y. S. \& McKay, G. Pseudo-second order model for sorption processes. Process Biochem 5, 451-465 (1999).

28. Kennedy, L. J., Vijaya, J. J., Kayalvizhi, K. \& Sekaran, G. Adsorption of phenol from aqueous solutions using mesoporous carbon prepared by two-stage process. Chem. Eng. J. 1-3, 279-287 (2007).

29. Langmuir, I. The adsorption of gases on plane surfaces of glass, mica and platinum. J. Am. Chem. Soc. 9, 1361-1403 (1918).

30. Hameed, B. H., Tan, I. A. W. \& Ahmad, A. L. Adsorption isotherm, kinetic modeling and mechanism of 2, 4, 6-trichlorophenol on coconut husk-based activated carbon. Chem. Eng. J. 2, 235-244 (2008).

31. Wu, X. P., Zhang, Q. X., Liu, C., Zhang, X. \& Chung, D. D. L. Carbon-coated sepiolite clay fibers with acid pre-treatment as low-cost organic adsorbents. Carbon 123, 259-272 (2017).

32. Hadi, P., Xu, M., Ning, C., Lin, C. S. K. \& Mckay, G. A critical review on preparation, characterization and utilization of sludgederived activated carbons for wastewater treatment. Chem. Eng. J. 260, 895-906 (2015).

33. Saleh, T. A., Adio, S. O., Asif, M. \& Dafalla, H. Statistical analysis of phenols adsorption on diethylenetriamine-modified activated carbon. J. Clean. Prod. 182, 960-968 (2018).

34. Abdel-Ghani, N. T., El-Chaghaby, G. A. \& Helal, F. S. Individual and competitive adsorption of phenol and nickel onto multiwalled carbon nanotubes. J. Adv. Res. 3, 405-415 (2015).

35. Yang, K., Wu, W., Jing, Q. \& Zhu, L. Aqueous adsorption of aniline, phenol, and their substitutes by multi-walled carbon nanotubes. Environ. Sci. Technol. 21, 7931-7936 (2008).

36. Yang, K., Yang, J., Jiang, Y., Wu, W. \& Lin, D. Correlations and adsorption mechanisms of aromatic compounds on a high heat temperature treated bamboo biochar. Environ. Pollut. 210, 57-64 (2016).

37. Noh, J. S. \& Schwarz, J. A. Estimation of the point of zero charge of simple oxides by mass titration. J. Colloid. Interface. Sci. 1, 157-164 (1989)

38. Boehm, H. P. Some aspects of the surface chemistry of carbon blacks and other carbons. Carbon 5, 759-769 (1994).

\section{Acknowledgements}

The authors appreciate the financial support of the National Key Research and Development Program (2018YFB0605200), the Natural Science Foundation of Jiangsu Province (BK20181142, BK20190015).

\section{Author contributions}

B.S. designed this study and wrote the paper. M.S. conducted the XPS and FTIR measurements and revised the paper. F.Y.M. and D.D.C. contributed to the sample preparation, carried out the SEM observations, and partially wrote the paper. F.S. and Y.X.W. carried out the adsorption experiments and prepared the figures and tables.

\section{Competing interests}

The authors declare no competing interests.

\section{Additional information}

Supplementary information is available for this paper at https://doi.org/10.1038/s41598-019-56425-8.

Correspondence and requests for materials should be addressed to M.S.

Reprints and permissions information is available at www.nature.com/reprints.

Publisher's note Springer Nature remains neutral with regard to jurisdictional claims in published maps and institutional affiliations.

Open Access This article is licensed under a Creative Commons Attribution 4.0 International License, which permits use, sharing, adaptation, distribution and reproduction in any medium or format, as long as you give appropriate credit to the original author(s) and the source, provide a link to the Creative Commons license, and indicate if changes were made. The images or other third party material in this article are included in the article's Creative Commons license, unless indicated otherwise in a credit line to the material. If material is not included in the article's Creative Commons license and your intended use is not permitted by statutory regulation or exceeds the permitted use, you will need to obtain permission directly from the copyright holder. To view a copy of this license, visit http://creativecommons.org/licenses/by/4.0/.

(C) The Author(s) 2019 